\title{
Child Abdominal Trauma Due to Attack of Cattles While Working on Farms in Burkina Faso
}

\author{
Souleymane Ouedraogo ${ }^{1}$, Cyprien Zaré ${ }^{*}$, Maurice Zida ${ }^{3}$, Julien T. Savadogo ${ }^{1}$, \\ Mamadou Windsouri ${ }^{1}$, Edgar Ouangre ${ }^{3}$, Emile Bandre ${ }^{3}$, Simon S. Traore ${ }^{3}$ \\ ${ }^{1}$ Department of Surgery, University Ouaga 1 Pr Joseph Ki Zerbo, Ouagadougou, Burkina Faso \\ ${ }^{2}$ Department of Surgery, University of Nazi Bony, Bobo-Dioulasso, Burkina Faso \\ ${ }^{3}$ Department of Surgery, University Ouaga Pr Joseph Ki Zerbo, Ouagadougou, Burkina Faso \\ Email: *zcyprien@yahoo.fr
}

How to cite this paper: Ouedraogo, S., Zaré, C., Zida, M., Savadogo, J.T., Windsouri, M., Ouangre, E., Bandre, E. and Traore, S.S. (2017) Child Abdominal Trauma Due to Attack of Cattles While Working on Farms in Burkina Faso. Surgical Science, 8, 481-487.

https://doi.org/10.4236/ss.2017.811053

Received: October 14, 2017

Accepted: November 22, 2017

Published: November 27, 2017

Copyright $\odot 2017$ by authors and Scientific Research Publishing Inc. This work is licensed under the Creative Commons Attribution International License (CC BY 4.0).

http://creativecommons.org/licenses/by/4.0/

(c) $\underset{\mathrm{EY}}{\mathrm{C}}$ Open Access

\begin{abstract}
Introduction: Cattle are strong animals very often used in agriculture in rural Africa. Unpredictable in their behavior, they regularly inflict injuries to farmers, some of whom are children in rural Africa. Objective: The purpose of this study was to describe the clinical, therapeutic and evolutionary aspects of abdominal trauma caused by bovidae to children on farms in Burkina Faso. Patients and Method: This is a descriptive study covering the period from January 2014 through December 2016 and was conducted in the General Surgery Unit of the Tenkodogo Regional Hospital in Burkina Faso. It included all patients under the age of 17 , victims of abdominal trauma by cattle on farms. Result: A total of 68 patients were identified, which is $3 \%$ of all patients under 17 admitted to the service during the same period. The average age of patients was 10.5 years, with a standard variation of 3.6 years. The majority $(73.5 \%)$ of the patients were boys. The main lesional mechanisms found were horn strokes (88.2\%). We noted 35 eviscerations without visceral perforation, 15 intestinal perforations, 6 hepatic wounds and 5 splenic wounds. In 7 cases, there were non-penetrating wounds. All patients underwent surgical intervention under anesthesia. The average length of hospital was 6 days. Two deaths were recorded, making a mortality rate of $3 \%$. Conclusion: Abdominal traumas of the child by attack of cattle are frequent during farm works in rural Burkina Faso. The injuries are sometimes serious. Wearing protective equipment for children should be considered during farm work.
\end{abstract}

\section{Keywords}

Abdominal Trauma, Cattle, Children, Field Work, Surgery 


\section{Introduction}

Children are regularly employed in farming in African rural areas. The undermechanization of agriculture leads to the use of bovid for plowing. These bovid are robust and unpredictable in their behavior. They regularly inflict trauma on farmers. These traumas are regularly reported in the medical papers [1] [2]. In the United States, about $1.7 \%$ of farmers are attacked by cattle each year, and most traumas are mild [3] [4] [5]. But in some parts of the world, these traumas are serious and can account for up to $25 \%$ of the causes for hospitalizations in some surgical departments [1]. While in Africa the existence of traumas caused by bovine on farms is known, the frequency and sternness of lesions are the least known [6] [7]. Some wound locations such as the abdomen are particularly dangerous, especially when it comes to children.

The aim of this study is to assess the frequency and severity of abdominal trauma caused by bovidae during farm work in the rural area of the central east of Burkina Faso, and then, make proposals for the protection of children.

\section{Patients and Methods}

\section{Type, site and period of study}

This is a descriptive study covering the period from 1 January 2014 to 31 December 2016. It was conducted in the General Surgery Unit of the Tenkodogo Regional Hospital in eastern Burkina Faso. The Tenkodogo regional hospital is a reference hospital for the entire Central East region of Burkina Faso, an agricultural region with 1.5 million inhabitants.

\section{Inclusion Criteria}

We have included in this study all patients under the age of 17 admitted for abdominal trauma caused by bovines during farm work.

\section{Exclusion Criteria}

Patients aged 17 and above were excluded.

\section{Data Collection and Analysis}

Data collection was prospective. For each patient, we collected data including age, sex, lesional mechanisms, clinical signs, results of complementary examinations, therapeutic modalities, and evolutionary complications. These data were collected on a pre-established form and analyzed through the Epi info software.

\section{Ethical aspects}

The study was authorized by the National Ethics Committee for Health Research in Burkina Faso. An authorization was obtained from the parent of each child before he was included in the study. Data collection was done anonymously and patient confidentiality was respected for all patients.

\section{Results}

\subsection{Epidemiological Aspects}

A total of 68 patients were included. These patients present for $3 \%$ of all patients under the age of 17 admitted during the same period in the service. The average 
age of the patients was 11.4 with the age of 5 years being the youngest and 16 years being the oldest. There were 18 girls (26.5\%) and 50 boys (73.5\%). The distribution of patients by age and sex is presented in Figure 1 .

\subsection{Clinical Aspects}

The average consultation time was 7 hours, with extremes of 2 and 11 hours. The lesional mechanisms found were horn strokes in 60 cases (88.2\%) and the association horn and stroke in 8 cases $(11.8 \%)$. At admission, all patients presented a normal state of consciousness. Clinical anemia (conjunctival pallor, tachypnea and tachycardia, arterial hypotension) was found in 14 patients (20.6\%). Two other patients (2.9\%) were admitted under hypovolemic shock. The hemodynamic status was normal in the remaining 52 patients. Skin lesions were most common in the umbilical region. The location of the wounds in relation to the quadrants of the abdomen is specified in the following Table 1.

All patients underwent a short resuscitation with initial correction of haemodynamic troubles and analgesic treatment. A blood check-up including blood 30

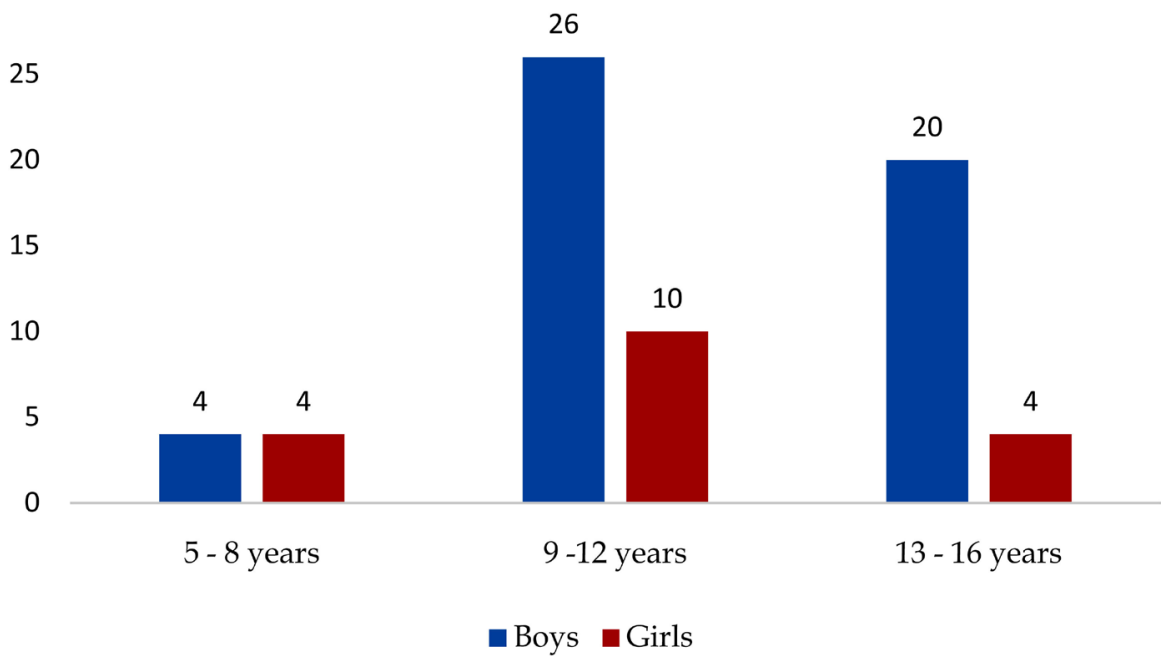

Figure 1. Distribution of patients by age and sex.

Table 1. Distribution of patients by location of skin injury on abdominal wall.

\begin{tabular}{ccc}
\hline Location of Skin Injury on Abdominal Wall & Size & Rate (\%) \\
\hline Umbilical region & 39 & 57.4 \\
Straight Hypochondrium & 8 & 11.8 \\
Left hypochondrium & 5 & 7.3 \\
Right iliac fossa & 2 & 2.9 \\
Left iliac fossa & 3 & 4,4 \\
Left flank & 7 & 10.3 \\
Posterior abdominal region & 4 & 5.9 \\
Total & 68 & 100 \\
\hline
\end{tabular}


count, serum creatinine, and blood glucose was performed in all patients. A complete clinical examination was then performed. This examination made it possible to retain the diagnosis of non-penetrating wound in 7 cases (ie 10.3\%). The remaining 61 cases (89.7\%), were abdominal penetrating wounds and then, an examination was performed in the operation room under anesthesia. Thirtyfive patients (51.5\%) had an evisceration with externalization of the small intestine or omentum, without intra-abdominal organ injury (Figure 2).

In 26 cases (44.8\%), perforation of an intra-abdominal viscus was associated. Perforations of the small intestine were the most common lesion. Figure 3 show the distribution of patients according to the affected organ.

\subsection{Therapeutic Aspects}

All patients underwent surgery. The average surgery time was 54 minutes with extremes of 36 and 109 minutes. In the case of a non-penetrating abdominal wound, a parietal repair was performed under general anesthesia. This repair consisted in a trimming, a reconstruction of the muscular and aponeurotic plans and an excision-suture of the cutaneous edges of the wound. In the case of a penetrating wound, an enlarged wound allowed the systematic exploration of the abdominal cavity and the repair of lesions at the same time. Thus, in the case of perforation of the colon or small intestine, the surgical treatment included cleansing in the peritoneal cavity, followed by a suture. Drainage of the abdo-

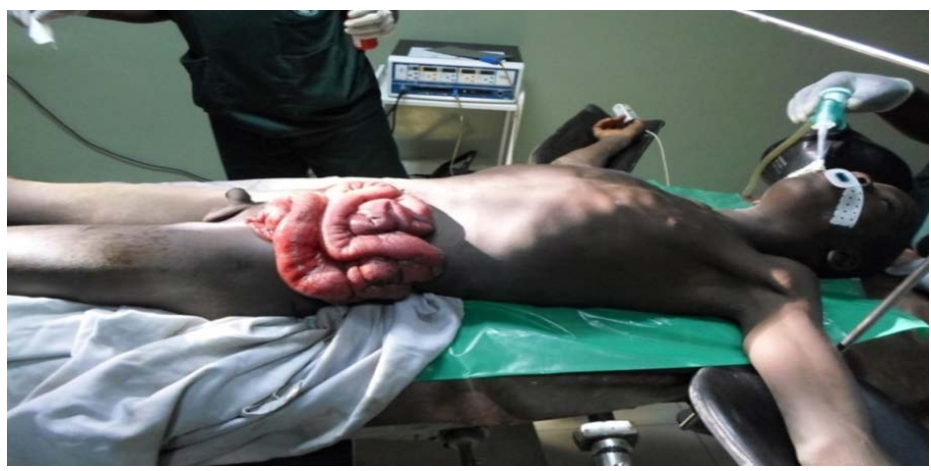

Figure 2. Evisceration in a 15-year-old adolescent.

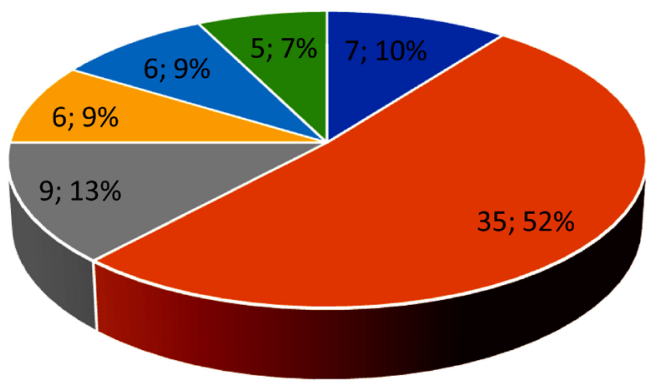

- Abdominal non penetrating wounds

- Eviscerations

- Small intestine perforations

- colon perforations

- Hepatic wounds

- splenic wounds

Figure 3. Distribution of patients according to the affected organ. 
minal cavity was associated. Hepatic packing was performed in patients with hepatic wounds. The lesions of the spleen were treated conservatively in 4 cases. Total splenectomy was performed in one patient

\subsection{Evolutionary Aspects}

The average hospital stay was 6 days. Two deaths were recorded, making a mortality of $3 \%$. There were 2 patients with hepatic wound admitted with hemorrhagic shock.

\section{Discussion}

Cattle injuries during farm work are a real risk for farmers [8] [9]. The frequency of these lesions in our context is probably underestimated, as only serious injuries are reverted to the hospital. This situation is due to the fact that populations in rural Africa are often far from health facilities. Non-serious injuries are often subject to self-medication and traditional medicine. In addition, hospital records do not include an item for identifying these specific trauma etiologies, and there are cases of bovine-trauma where circumstances have not been clearly stated in the clinical records. In Sweden, rural hospitals have established specific records to identify specific contexts in which animal attack wounds occur [2] [5]. Patients were relatively young in our series, with an average age of 11.4 years. In the West, the average age is between 30 and 50 years [8] [10]. The proportion of children under 17 is only $8 \%$ in the United States [10] [11]. In the Western documentation, cattle trauma is dominated by lesions of the upper limbs, especially hands and wrist [10] [12]. We noted a predominance of eviscerations without intra-abdominal visceral perforation. In the medical literature it is mentioned that most eviscerations are not accompanied by intra-abdominal visceral perforation [Patel]. We reported laparotomy in all cases where the wound was deep. The therapeutic attitude before a wound of the abdomen remains controversial [10] [13]. The present tendency is to favor non-operative treatment in the absence of obvious indications such as hemodynamic instability, acute generalized peritonitis [2] [13]. In a context of limited means, it was not possible to carry out specialized imaging examinations such as CT or MRI. These two exams would have allowed us to better define the lesional diagnosis and avoid exploratory laparotomies. We noted a mortality of $3 \%$. In the West, mortality is almost zero [4] [12]. This difference is firstly due to the location of the lesions in our context. Moreover, the lack of technical support in our environment does not allow adequate management of certain complex wounds.

\section{Conclusion}

Cattle trauma is common in rural areas. Their frequency is probably underassessed in our health facilities. Injured lesions are often very serious. In Burkina Faso, these lesions almost affect exclusively children. A reflection should be carried out to train farms children on the behaviors of cattle and the wearing of 
protective equipment. This study was conducted in an urban hospital. It probably did not take into account all the cattle's related in children. A study in rural areas would provide additional data.

\section{Conflict of Interest}

None.

\section{References}

[1] Nogalski, A., Jankiewicz, L., Cwik, G., et al. (1007) Animal Related Injuries Treated at the Department of Trauma and Emergency Medicine, Medical University of Lublin. Annals of Agricultural and Environmental Medicine, 14, 57-61.

[2] Bjornstig, U., Eriksson, A. and Ornehult, L. (1991) Injuries Caused by Animals. Injury, 22, 295-298. https://doi.org/10.1016/0020-1383(91)90009-4

[3] Sprince, L., Park, H., Zwerling, C., et al. (2003) Risk Factors for Animal-Related Injury among Iow a Large-Livestock Farmer: A Case-Control Study Nested in the Agricultural Health Study. The Journal of Rural Health, 19, 165-173. https://doi.org/10.1111/j.1748-0361.2003.tb00558.x

[4] Lindsay, S., Selvaraj, S., Macdonald, J.W., et al. (2004) Injuries to Scottish Farmers While Tagging and Clipping Cattle: A Cross-Sectional Survey. Occupational Medicine, 54, 86-91. https://doi.org/10.1093/occmed/kqh032

[5] Ornehult, L., Eriksson, A. and Björnstig, U. (1989) Fatalities Caused by Nonvenomous Animals: A Ten-Year Summary from Sweden. Accident Analysis \& Prevention, 21, 377-381. https://doi.org/10.1016/0001-4575(89)90029-8

[6] Gilyoma, J.M., Mabula, J.B. and Chalya, P.L. (2013) Animal-Related Injuries in a Resource-Limited Setting: Experiences from a Tertiary Health Institution in Northwestern Tanzania. World Journal of Emergency Surgery, 8, 7. https://doi.org/10.1186/1749-7922-8-7

[7] Eid, H.O., Ashraf, A.F. and Abu-Zidan, F.M. (2015) Epidemiology of Animal-Related Injuries in a High-Income Developing Country. Ulus Travma Acil Cerrahi Derg, 21, 134-138.

[8] Colin, G.M., Ciara, M.G., Natasha, O. and Paul, H. (2010) Cow-Related Trauma: A 10-Year Review of Injuries Admitted to a Single Institution. Injury - International Journal of the Care of the Injured, 41, 548-550. https://doi.org/10.1016/j.injury.2009.08.006

[9] Emet, M., Beyhun, N.E., Kosan, Z., Aslan, S., Uzkeser, M. and Cakir, Z.G. (2009) Animalrelated Injuries: Epidemiological and Meteorological Features. Annals of Agricultural and Environmental Medicine, 16, 87-92.

[10] Martin, W. and Ethan, M. (2011) Cattle Associated Trauma-A One-Year Prospective Study of All Injuries. Injury - International Journal of the Care of the Injured, 42, 1084-1087. https://doi.org/10.1016/j.injury.2011.02.019

[11] Hendricks, K. and Adekoya, N. (2001) Non-Fatal Animal Related Injuries to Youth Occurring on Farms in the United States, 1998. Injury Prevention, 7, 307-311. https://doi.org/10.1136/ip.7.4.307

[12] Dogan, K., Demirci, S. and Erkol, Z. (2008) Injuries and Deaths Occurring as a Result of Bull Attack. Journal of Agromedicine, 13, 191-196. https://doi.org/10.1080/10599240802405975

[13] Patel, P., Gadhavi, J. and Parmar, H. (2016) A Study of Blunt and Penetrating Ab- 
dominal Trauma, Its Various Patterns of Injuries, and Its Management. International Journal of Medical Science and Public Health, 5, 1309-1312.

https://doi.org/10.5455/ijmsph.2016.06082015193 